Available online at http://jurnal.stmikroyal.ac.id/index.php/jurteksi

\title{
PENERAPAN METODE SIMPLE ADDITIVE WEIGHTING SEBAGAI STRATEGI PEMBINAAN KECERDASAN ANAK
}

\author{
Muhammad Ardiansyah Sembiring \\ Program Studi Sistem Informasi, STMIK Royal Kisaran \\ email: adinmantap88@gmail.com
}

\begin{abstract}
Kindergarten is an early childhood education that has an important role in developing the child's personality and preparing them to enter the next education level. Kindergarten is the first formal education to enter children aged 4-6 years, until entering primary education. Children at 4-6 years of age usually have problems with non normative behaviors, behavior can be seen from the level of development or have difficulty in adjusting either at study time (concentration) or in play activities at school or at home. To find out whether the child is having problems or not, the educator needs to understand and assess the child's development in all aspects. Decision support system is a system that can be used as a tool to determine the level of intelligence of children by providing an assessment of the child. The method used by the author is the method of Simple Additive Weighting (SAW) or better known as the weighted sum. Output in this method is the values that can provide benefits for researchers in knowing the child's intelligence to be held special coaching for children who have problems in its development. Quick and precise decisions become an important issue in a study. Data analysis is done by comparing between children. The result of SAW method analysis is a conclusion that helps teachers / educators to know the intelligence of their students.
\end{abstract}

Keywords: decision support system, SAW, kindergarten intelligence.

\begin{abstract}
Abstrak: Taman kanak-kanak merupakan jenjang pendidikan anak usia dini yang memiliki peran penting dalam mengembangkan kepribadian anak serta mempersiapkan mereka untuk memasuki jenjang pendidikan selanjutnya. TK adalah jenjang pendidikan formal pertama yang memasuki anak usia 4-6 tahun, sampai memasuki pendidikan dasar. Anak pada usia 4-6 tahun biasanya memiliki masalah pada prilaku non normatif, prilaku dapat dilihat dari tingkat perkembangannya atau mengalami kesulitan dalam menyesuaikan diri baik pada waktu belajar (konsentrasi) maupun dalam aktivitas bermain disekolah atau dirumah. Untuk mengetahui apakah anak bermasalah atau tidak, pendidik perlu memahami dan memberikan penilaian terhadap perkembangan anak dalam segala aspek. Sistem pendukung keputusan merupakan sistem yang dapat digunakan sebagai alat bantu untuk mengetahui tingkat kecerdasan anak dengan memberikan penilaian terhadap anak tersebut. Metode yang digunakan penulis adalah metode Simple Additive Weighting (SAW) atau yang lebih dikenal dengan penjumlahan berbobot. Output dalam metode ini merupakan nilai-nilai yang dapat memberikan keuntungan bagi peneliti dalam mengetahui kecerdasan anak guna diadakan pembinaan khusus untuk anak-anak tk yang memiliki masalah dalam perkembangannya. Keputusan yang cepat dan tepat menjadi persoalan penting dalam sebuah penelitian. Analisa data dilakukan dengan cara membandingkan antara anak. Hasil dari analisa metode SAW ini menjadi kesimpulan yang membantu guru/pendidik untuk mengetahui tingat kecerdasan anak didiknya.
\end{abstract}

Kata kunci: sistem pendukung keputusan, $S A W$, kecerdasan anak TK 
Available online at http://jurnal.stmikroyal.ac.id/index.php/jurteksi

\section{PENDAHULUAN}

Anak adalah amanat bagi kedua orang tuanya, kewajiban orang tua/ pendidik memberikan pendidikan kepada anak merupakan urusan yang sangat berharga dan menempati prioritas tertinggi. Qalbu seorang anak yang masih bersih bak permata yang tidak ternilai harganya, bila ia dididik dan dibiasakan melakukan kebaikan niscaya ia akan tumbuh menjadi baik, sebaliknya bila ia dididik dan dibiasakan dengan perbuatan jelek, maka ia juga akan terbiasa dengan kebiasaan buruknya tersebut. Setiap anak memiliki karakteristik yang berbeda-beda. Proses utama perkembangan anak merupakan hal yang saling berkaitan antara proses biologis, proses sosio emosional dan proses kognitif. Ketiga hal tersebut akan saling berpengaruh satu sama lain dan sepanjang perjalanan hidup manusia. Selama proses perkembangan selanjutnya.

Permasalahan yang dihadapi anak dapat dilihat melalui tingkah laku anak pada saat mengikuti proses belajar dikelas atau pada saat bermain. Berbagai faktor yang menyebabkan permasalahan perkembangan anak tidak hanya mengahambat perkembangan emosi dan sosisalnya, akan tetapi juga menghambat perkembangan fisik, intelektual, kognitif, dan bahasa. Oleh karena itu dalam menangani permasalahan anak tidak bisa hanya menyelesaikan masalah satu aspek saja, namun harus memantau semua kepirbadian anak guna diberikan penilian terhadap perkembangannya.

Dengan adanya metode Simple Additive Weighting (SAW), peneliti berinisiatif membuat sebuah penelitian tentang penilaian kecerdasan pada anak taman kanak-kanak yang dapat dijadikan pedoman nantinya untuk para pendidik agar lebih fokus terhadap anak yang memiliki tingkat kecerdasan yang rendah. Tentunya analisa dilakukan berdasarkan tingkah laku dan proses belajar anak-anak selama didalam lingkungan taman kanak- kanak. Dan tentunya anak-anak tersebut sangat diperlukan sebagai generasi bangsa yang menjadi persediaan bagi negri ini untuk mewujudkan negri yang cemerlang.

\section{Sistem Pendukung Keputusan (Decision Support System)}

Penyelesaian Sistem Pendukung

Keputusan dapat dilakukan dengan banyak metode tergantung pada banyaknya kriteria. Untuk pengambilan keputusan dengan satu kriteria/single objective decision making dapat dilakukan dengan metode decision tree dan influence diagram. Sedangkan untuk pengambilan keputusan dengan banyak kriteria/multiple attribute decision making dapat menggunakan banyak metode multiple attribute utility theory, analytical hierarchy process, elimination and choice translating reality methods, the preference ranking organization methods for enrichment evaluation, dan other multiple attribute decision making. Metode MADM yang paling banyak digunakan adalah AHP. (Pirdashti, 2009).

Sistem Pendukung Keputusan memiliki beberapa karakteristik yaitu sebagai berikut.

1. SPK ditujukan untuk membantu keputusan-keputusan yang kurang terstruktur dan umumnya dihadapi oleh para manajer yang berada di tingkat puncak.

2. SPK merupakan gabungan antara kumpulan model kualitatif dan kumpulan data.

3. SPK memiliki fasilitas interaktif yang dapat mempermudah hubungan antara manusia dengan komputer.

4. SPK bersifat luwes dan dapat menyesuaikan dengan perubahanperubahan yang terjadi.

\section{Kecerdasan Anak}

Kecerdasan adalah yang digunakan untuk menjelaskan sifat pikiran yang mencakup sejumlah kemampuan, seperti kemampuan menalar, merencanakan, me 
Available online at http://jurnal.stmikroyal.ac.id/index.php/jurteksi

mecahkan masalah, berpikir abstrak, memahami gagasan, menggunakan bahasa, dan belajar. Kecerdasan erat kaitannya dengan kemampuan kognitif yang dimiliki oleh individu. Kecerdasan dapat diukur dengan menggunakan alat psikometri yang biasa disebut sebagai tes IQ. Ada juga pendapat yang menyatakan bahwa IQ merupakan usia mental yang dimiliki manusia berdasarkan perbandingan usia kronologis.

Setiap anak memiliki kecerdasan. Hanya saja, ada anak yang hanya menonjol pada satu atau lebih jenis kecerdasan tertentu. Untuk itu, orangtua seharusnya mengenali jenis kecerdasan anak, kemudian membantu mengasah kecerdasannya. (Thomas, 2002).

Setiap anak harus mendapat dukungan dan perhatian dari orang disekitarnya untuk memantau gerak gerik, tingkah laku, dan cara belajar anak agar mengetahui bagaimana tingkat dan kemampuan anak dalam berfikir.

\section{Taman Kanak-Kanak}

Pendidikan Taman Kanak-kanak

(TK) memberi kesempatan untuk mengembangkan kepribadian anak. Oleh karena itu, pendidikan anak usia dini PAUD khususnya TK perlu menyediakan berbagai kegiatan yang dapat mengembangkan berbagai aspek perkembangan yang meliputi aspek kognitif, bahasa, sosial, emosi, fisik, dan motorik (Suriansyah, 2011).

Pembelajaran di taman kanakkanak TK hendak disesuaikan dengan usia anak yang masih suka bemain, kegiatan pembelajaran Calistung (baca tulis berhitung) harus diintegrasikan dalam kegiatan bermain, dalam program eksplorasi maupun dalam kegiatan sentra. Dalam kegiatan belajar berhitung misalnya dapat dilakukan dengan permainan-permainan berhitung, ini tidak hanya berkaitan dengan kemampuan kognitif saja, tetapi juga kesiapan mental sosial dan emosional serta untuk menumbuhkan kecerdasan anak.

\section{Simple Additive Weighting (SAW)}

Merupakan metode penjumlahan terbobot. Konsep dasar metode SAW adalah mencari penjumlahan terbobot dari rating kinerja pada setiap alternatif pada semua kriteria (Kusumadewi, 2006).

Metode SAW membutuhkan proses normalisasi matrik keputusan $(X)$ ke suatu skala yang dapat diperbandingkan dengan semua rating alternatif yang ada. Metode SAW mengenal adanya 2 (dua) atribut yaitu kriteria keuntungan (benefit) dan kriteria biaya (cost). Perbedaan mendasar dari kedua kriteria ini adalah dalam pemilihan kriteria ketika mengambil keputusan.

Adapun langkah penyelesaian dalam menggunakannya adalah:

1. Menentukan alternatif, yaitu Ai.

2. Menentukan kriteria yang akan dijadikan acuan dalam pengambilan keputusan, yaitu $\mathrm{Cj}$

3. Memberikan nilai rating kecocokan setiap alternatif pada setiap kriteria.

4. Menentukan bobot preferensi atau tingkat kepentingan (W) setiap kriteria.

$$
\mathrm{W}=[\mathrm{W} 1, \mathrm{~W} 2, \mathrm{~W} 3, \ldots, \mathrm{WJ}]
$$

5. Membuat tabel rating kecocokan dari setiap alternatif pada setiap kriteria.

6. Membuat matrik keputusan (X) yang dibentuk dari tabel rating kecocokan dari setiap alternatif pada setiap kriteria. Nilai $X$ setiap alternatif (Ai) pada setiap kriteria $(\mathrm{Cj})$ yang sudah ditentukan, dimana, $\mathrm{i}=1,2, \ldots \mathrm{m}$ dan $\mathrm{j}=1,2, \ldots \mathrm{n}$.

7. Melakukan normalisasi matrik keputusan dengan cara menghitung nilai ratingkinerja ternomalisasi (rij) dari alternatif Ai pada kriteria $\mathrm{Cj}$.

Keterangan:

a. Kriteria keuntungan apabila nilai memberikan keuntungan bagi pengambil keputusan, sebaliknya kriteria biaya apabila menimbulkan biaya bagi pengambil keputusan.

b. Apabila berupa kriteria keuntungan maka nilai dibagi dengan 
nilai dari setiap kolom, sedangkan untuk kriteria biaya, nilaidari setiap kolom dibagi dengan nilai $\mathrm{Xij}$.

8. Hasil dari nilai rating kinerja ternomalisasi (rij) membentuk matrik ternormalisasi $(\mathrm{R})$

9. Hasil akhir nilai preferensi (Vi) diperoleh dari penjumlahan dari perkalian elemen baris matrik ternormalisasi (R) dengan bobot preferensi (W) yang bersesuaian eleman kolom matrik (W).

Hasil perhitungan nantinya nilai $\mathrm{Vi}$ yang lebih besar mengindikasikan bahwa alternatif Ai merupakan alternatif terbaik (Kusumadewi, 2006).

\section{METODOLOGI}

\section{Jenis dan Sumber Data}

Jenis data yang dikumpulkan dan dianalisis adalah bersumber dari laporan belajar anak selama ditaman kanak-kanak yang diberikan oleh guru/pendidik, dan data lainnya.

\section{Lokasi Penelitian}

Penelitian ini dilakukan didae-rah Kec. Air Batu yaitu di TK Sanggar Bambini Air Batu dengan mewawancarai guru/pendidik TK Sanggar Bambini Air Batu dan melalui data laporan belajar anak selama ditaman kanak-kanak yang diberikan oleh guru/pendidik TK Sanggar Bambini Air Batu.

\section{Populasi dan Sampel Penelitian}

Populasi penelitian ini adalah laporan yang diberikan oleh seluruh guru/pendidik yang mengajar di TK Sanggar Bambini Air Batu dan melihat kondisi anak yang ada di TK Sanggar Bambini Air Batu, dan pada akhirnya dapat disimpulkan melaku-kan penilaian kecerdasan kepada anak taman-kanak sangat dibutuhkan oleh pihak guru/ pendidik.

Sesuai dengan kebutuhan dalam penelitian ini langkah-langkah penelitiannya adalah sebagai berikut:

a. Menentukan kecerdasan anak tingkat nol kecil pada taman kanak-kanak dengan kriteria-kriterianya adalah kemampuan berhitung, kemampuan membaca, kemampuan berbahasa, pembentukan spritual, dan pembentukan prilaku sebagai standart utama kualitas sebuah penilaian kecerdasan anak. Dan alternatif pada TK Sanggar Bambini Air Batu, yaitu: murid nol kecil yang ada di TK Sanggar Bambini.

b. Menentukan jenis-jenis kriteria yang akan menjadi persyaratan dalam penilaian kecerdasan anak taman kanak-kanak dan menen-tukan kriteria-kriteria tersebut dalam bentuk penjumlahan terbo-bot.

\section{HASIL DAN PEMBAHASAN}

Analisa acuan dalam membangun sistem pendukung keputusan ini berdasarkan penilaian secara umum dilakukan pada proses belajar anak tingkat nol kecil di TK Sanggar Bambini Air Batu. Dimana dalam penilaian ini setiap anak dinilai berdasarkan kriteria dan alternatif, di bawah ini adalah tabel kriteria dan alternatif yang akan di uji dengan metode Simple Additive Weighting $(S A W)$. Diperlukan kriteria-kriteria dan bobot untuk melakukan perhitungannya sehingga akan didapat alternatif terbaik. Dalam metode ini ada bobot dan kriteria yang dibutuhkan untuk menentukan penilaian anak TK yang akan menjadi anak terbaik dan anak yang perlu pembinaan khusus oleh guru/pendidik. Adapun kriteria dan alternatifnya adalah:

Tabel 1. Kriteria

\begin{tabular}{ll}
\hline K1 & Kemampuan Berhitung \\
\hline K2 & Kemampuan Membaca \\
\hline K3 & Kemampuan Berbahasa \\
\hline K4 & Pembentukan Spritual \\
\hline K5 & Pembentukan Prilaku \\
\hline
\end{tabular}


Available online at http://jurnal.stmikroyal.ac.id/index.php/jurteksi

\begin{tabular}{ll}
\hline \hline & Tabel 2 Arternatif \\
\hline A1 & Adwa Damanik \\
\hline A2 & Aldi Falasyah \\
\hline A3 & Al Isnaini \\
\hline A4 & Aqib Sandro Sitorus \\
\hline A5 & Attala Rafa \\
\hline A6 & Fatih Farhan \\
\hline A7 & Kevin Lubis \\
\hline A8 & M. Fahri Anan \\
\hline A9 & Putri Zahra Lestari \\
\hline A10 & Rafa Dwinanda Prabudi \\
\hline A11 & Seni Warnati \\
\hline A12 & Tanisa Zira \\
\hline A13 & Tasya Fadhila \\
\hline A14 & Wisnu Candra Winata \\
\hline A15 & Yani Mulyani
\end{tabular}

benefit $=$ Maksimum). Nilai crips $(X i j)$ dari setiap kolom atribut dibagi dengan nilai crips Max (Max Xij dari setiap kolom). Gambar normalisasi matriks pada setiap nilai alternative tertuang pada tabel 5 .

Tabel 4 Alternatif dan Kriteria

\begin{tabular}{cccccc}
\hline $\begin{array}{c}\text { Alternatif/ } \\
\text { Kriteria }\end{array}$ & K1 & K2 & K3 & K4 & K5 \\
\hline A1 & 10 & 10 & 8 & 9 & 5 \\
\hline A2 & 8 & 7 & 5 & 8 & 5 \\
\hline A3 & 10 & 9 & 9 & 7 & 6 \\
\hline A4 & 7 & 7 & 5 & 8 & 7 \\
\hline A5 & 5 & 7 & 7 & 8 & 5 \\
\hline A6 & 9 & 9 & 6 & 8 & 9 \\
\hline A7 & 8 & 9 & 5 & 5 & 5 \\
\hline A8 & 10 & 10 & 7 & 10 & 7 \\
\hline A9 & 5 & 5 & 6 & 8 & 6 \\
\hline A10 & 6 & 7 & 5 & 5 & 7 \\
\hline A11 & 5 & 5 & 7 & 9 & 9 \\
\hline A12 & 7 & 8 & 8 & 10 & 10 \\
\hline A13 & 8 & 10 & 8 & 8 & 10 \\
\hline A14 & 7 & 9 & 7 & 8 & 9 \\
\hline A15 & 7 & 8 & 5 & 5 & 8 \\
\hline & & & & &
\end{tabular}

Tabel 5. Normalisasi Matriks (R)

Berdasarkan data yang ada:

1. Kita tentukan dari kriteria tersebut mana yang termasuk cost dan benefit. Dalam melakukan peni-laian kecerdasan anak TK semua kriteria tergolong pada benefit.

2. Mengisi nilai bobot kepentingan dari kriteia tersebut.

3. Mencari nilai kepentingan dengan membagi bobot kepentingan dengan jumlah bobot kepentingan.

Tabel 3 Bobot Kepentingan (W)

\begin{tabular}{ccc}
\hline Kriteria & Kepentingan & $\begin{array}{c}\text { Bobot } \\
\text { Kepentingan }\end{array}$ \\
\hline K1 & 5 & 0,33 \\
\hline K2 & 4 & 0,27 \\
\hline K3 & 2 & 0,13 \\
\hline K4 & 3 & 0,20 \\
\hline K5 & 1 & 0,07 \\
\hline Jumlah & 15 & 1,00 \\
\hline
\end{tabular}

4. Kemudian dibentuk matriks keputusan yang dikonversikan dengan nilai crips, seperti gambar 4 .

Melakukan normalisasi matriks dengan cara menghitung nilai rating kinerja ternormalisasi (rij) dari alternatif Ai pada atribut $\mathrm{Cj}$ berdasarkan persamaan yang disesuaikan dengan jenis atribut, dan pada hal ini semua atribut merupakan keuntungan/benefit (atribut keuntungan/

\begin{tabular}{|c|c|c|c|c|c|}
\hline & K1 & $\mathrm{K} 2$ & K3 & K4 & K5 \\
\hline A1 & 1,00 & 1,00 & 0,89 & 0,90 & 0,50 \\
\hline A2 & 0,80 & 0,70 & 0,56 & 0,80 & 0,50 \\
\hline A3 & 1,00 & 0,90 & 1,00 & 0,70 & 0,60 \\
\hline A4 & 0,70 & 0,70 & 0,56 & 0,80 & 0,70 \\
\hline A5 & 0,50 & 0,70 & 0,78 & 0,80 & 0,50 \\
\hline A6 & 0,90 & 0,90 & 0,67 & 0,80 & 0,90 \\
\hline A7 & 0,80 & 0,90 & 0,56 & 0,50 & 0,50 \\
\hline A8 & 1,00 & 1,00 & 0,78 & 1,00 & 0,70 \\
\hline A9 & 0,50 & 0,50 & 0,67 & 0,80 & 0,60 \\
\hline A10 & 0,60 & 0,70 & 0,56 & 0,50 & 0,70 \\
\hline A11 & 0,50 & 0,50 & 0,78 & 0,90 & 0,90 \\
\hline A12 & 0,70 & 0,80 & 0,89 & 1,00 & 1,00 \\
\hline A13 & 0,80 & 1,00 & 0,89 & 0,80 & 1,00 \\
\hline A14 & 0,70 & 0,90 & 0,78 & 0,80 & 0,90 \\
\hline A15 & 0,70 & 0,80 & 0,56 & 0,50 & 0,80 \\
\hline
\end{tabular}

Dengan nilai bobot (W). Penjumlahan hasil kali matriks ternormalisasi menghasilkan angka seperti pada tabel 6 . 
Available online at http://jurnal.stmikroyal.ac.id/index.php/jurteksi

\begin{tabular}{ccc}
\hline \multicolumn{3}{c}{ Tabel 6. Nilai Preverensi dan Rangking } \\
\hline Alternatif & $\begin{array}{c}\text { Preverensi } \\
\text { (Vi) }\end{array}$ & Rangking \\
\hline A1 & 0,93 & 1 \\
\hline A2 & 0,72 & 2 \\
\hline A3 & 0,89 & 3 \\
\hline A4 & 0,70 & 4 \\
\hline A5 & 0,65 & 5 \\
\hline A6 & 0,85 & 6 \\
\hline A7 & 0,71 & 7 \\
\hline A8 & 0,95 & 8 \\
\hline A9 & 0,59 & 9 \\
\hline A10 & 0,61 & 10 \\
\hline A11 & 0,64 & 11 \\
\hline A12 & 0,83 & 12 \\
\hline A13 & 0,88 & 13 \\
\hline A14 & 0,80 & 14 \\
\hline A15 & 0,67 & 15 \\
\hline
\end{tabular}

\section{SIMPULAN}

Dari hasil pengujian sistem yang telah dilakukan, maka dapat diambil beberapa simpulan diantarnya sebagai berikut:

1. Metode SAW dapat di implementasikan pada aplikasi sistem pendukung keputusan penilaian kecerdasan pada anak taman kanakkanak.

2. Dari hasil penelitian dapat diketahui bahwa anak yang memiliki kecerdasan tertinggi pada kelas nol kecil TK Sanggar Bambini Air Batu adalah anak yang bernama M. Fahri Anan dengan memperoleh nilai sebesar 0,95.

3. Anak-anak yang memiliki kecerdasan rendah tingkat sepuluh ke bawah akan diberi perhatian khusus oleh guru/pendidik untuk lebih dibina kembali agar sesuai dengan anak-anak lainnya.

\section{DAFTAR PUSTAKA}

Daihani, D.U. (2001). Komputerisasi Pengambilan Keputusan. Jakarta: Elexmedia Komputindo.

Pirdashti, M., Ghadi, A., Mohammadi M., \& Shojatalab G. (2009). Sistem Pendukung Keputusan. Bandung: Remaja Rosdakarya.

Mulyana, S. (2000). Nilai dan Norma Kehidupan. Yogyakarta: Pedagogia.
Thomas, A. (2002). Bermain Kreatif Berbasis Kecerdasan Jamak. Jakarta:Gramedia.

Anderson, A. (1993). Ilmu Pendidikan. Jakarta: Rineka Cipta.

Suriansyah. (2011). Dasar-Dasar Pendidikan Anak. Yogyakarta: Gema Insani.

Kusumaderi, S. (2006). Fuzzy MultiAttribute Decision Making (Fuzzy MADM). Graha Ilmu, Yogyakarta. 
Available online at http://jurnal.stmikroyal.ac.id/index.php/jurteksi 
Jurnal Pena Edukasi

Vol. 4 No. 2, Maret 2017
ISSN 2407-0769 e-ISSN 2549-4694 